Valerio Vitor Bonelli ${ }^{1}$

Antonio Robles $\mathrm{Jr}^{2}$

\title{
A sustentabilidade via controles estratégicos dos custos ambientais
}

Recebido em: 03/12/2012 - Aprovado em: 16/12/2012 - Disponibilizado em: 26/12/2012

\section{Resumo}

O objetivo do presente artigo esta fundamentado na necessidade da implantação de um sistema de apuração dos custos ambientais em uma organização, demonstrar a necessidade de uso dos relatórios como ferramenta aos gestores para acompanhamento do comportamento destes custos sempre visando a melhoria contínua e a excelência na qualidade total. O sistema de custos proposto toma por base a contabilidade por atividades, tendo em vista propiciar informações aos gestores e colaboradores, facilitando e motivando a tomada de decisões mais corretas dentro do atual ambiente, de um lado mais competitivo, porém de outro lado mais responsável com a preservação do meio ambiente rumo à sustentabilidade empresarial. Propõe a definição de um Sistema de Informações Ambientais Gerenciais (SIAG), monitorado pela Controladoria da empresa.
Pallavras-chave: Sustentabilidade, Custos Ambientais, Melhoria Contínua.

Abstract

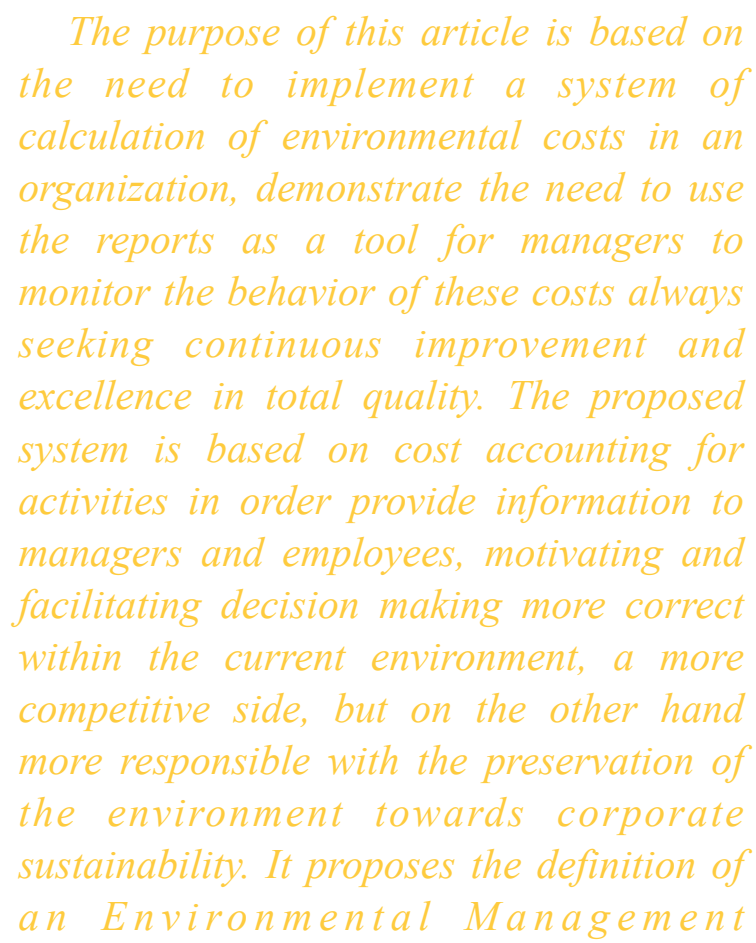

\footnotetext{
${ }^{1}$ Doutorando em Ciências Sociais pela PUC/SP, Mestre em Controladoria e Contabilidade Estratégica pela Fecap/Facesp, graduadoem Ciências Contábeis, Administração de Empresas, com Pós-graduação em Finanças, Membro da ABCAssociacão Brasileira de Custos. Professor Universitário na PUC/SP. Co-autor do livro Gestão da Qualidade e do Meio Ambiente: Enfoque Econômico, Financeiro e Patrimonial, pela Editora Atlas.

2 Doutor e Mestre em Contabilidade e Controladoria pela Universidade de São Paulo; Autor dos livros: Custos da Qualidade - Uma Estratégia para a Competição Global, Custos da Qualidade - Aspectos Econômicos da Gestão da Qualidade e da Gestão Ambiental e Co-autor dos livros: Alquimia de uma Corporação - A Magia de um Treinamento e Contabilidade de Custos: Temas Atuais. Professor na USP e no programas de Graduação e de Pós-Graduação Mestrado na PUCSP. Coordenador do curso de Ciências Contábeis da PUCSP. Assistente Doutor da Universidade de São Paulo, Avaliador de IES e cursos do INEP.
} 
Information System (SIAG), monitored by the Controller of the company.

\section{Introducão}

A internalização dos custos ambientais é uma maneira de equilibrar as forças de mercado e de distribuir mais equitativamente os danos que a sociedade esta suportando como efeitos da modificação da qualidade do meio ambiente. As experiências desenvolvidas em todo o mundo quanto aos instrumentos de interiorização dos custos ambientais mostram que as mudanças no sentido de tentar conciliar os diversos interesses envolvidos na questão já estão sendo efetuadas, colocando a todos os agentes principalmente não industriais o desafio de participar do processo e elevar seus níveis de percepção e atuação. Trata-se, porém, de iniciativa em desenvolvimento e muito ainda deve ser feito no sentido da busca da qualidade de vida para toda a população. $\mathrm{O}$ meio ambiente tornou-se um elementochave para a reformulação dos valores $\mathrm{e}$ vigentes na sociedade e estabelecerem-se novas formas de pensamento e ação em todas as práticas produtivas.

\section{Conceito em gestão ambiental}

A Gestão Ambiental consiste de um conjunto de medidas e procedimentos bem definidos e adequadamente aplicados que visam a reduzir e controlar os impactos introduzidos por um empreendimento sobre o Meio Ambiente. O ciclo da Gestão Ambiental, para que haja eficácia, deve cobrir, desde a fase de concepção do projeto até a eliminação efetiva e contínua dos resíduos gerados pelo empreendimento
Keywords: Sustainability, Environmental Costs, Continuous Improvement.

depois de implantado, durante toda sua vida útil, devendo também assegurar a melhoria contínua das condições de segurança, higiene e saúde ocupacional de todos os seus empregados e um relacionamento sadio com os segmentos da sociedade que interagem com esse empreendimento e a empresa. A Gestão Ambiental exige, como premissa básica, um comprometimento da alta direção da empresa e de seus acionistas com o estabelecimento de uma Política Ambiental clara e definida que irá nortear as atividades da organização com relação ao Meio Ambiente assumindo compromisso formal com a sociedade, definindo suas intenções e princípios com relação a seu desempenho ambiental.

\subsection{Responsabilidade social}

A responsabilidade social, como é chamada com frequência, implica um sentido de obrigação para com a sociedade. Esta responsabilidade assume diversas formas, entre as quais se incluem proteção ambiental, projetos filantrópicos e educacionais, planejamento da comunidade, equidade nas oportunidades de emprego, serviços sociais em geral, de conformidade com o interesse público.

Essa responsabilidade social das corporações, que excede a produção de bens e serviços, tem-se intensificado nas últimas décadas, notadamente a partir dos anos 60 , em respostas às mudanças ocorridas nos valores de nossa sociedade. Mudanças essas que incluem a responsabilidade de ajudar a sociedade a resolver alguns de seus problemas sociais, 
muitos dos quais as próprias organizações ajudaram a criar.

A justificativa para o sentido de responsabilidade social por parte da empresa fundamenta-se na liberdade que a sociedade concede à empresa para existir. Podemos considerar a existência de um contrato social. Uma empresa, como outras organizações legítimas, tem a liberdade de existir e trabalhar por um objetivo legítimo. O pagamento dessa liberdade é a contribuição da empresa para a sociedade.

Além disso, segundo Donaire (1995:20), "os termos desse contrato não são permanentes, mudam com o tempo. Atualmente esta claro que os termos do contrato entre as organizações e a sociedade estão de fato sofrendo substancias e importantes modificações. Os novos termos desse contrato baseiam-se na visão de que as empresas que tem finalidade unicamente econômica acabam acarretando alguns efeitos à sociedade ou à parte dela que representam um custo social para todos. Nesse sentido, o crescimento econômico não esta ligado, como antigamente se apregoava, ao progresso social. Em muitos casos, o crescimento esta afeto à deterioração física do ambiente, a condições insalubres de trabalho, exposição a substâncias tóxicas, discriminação a certos grupos sociais, deterioração urbana e outros problemas sociais".

Esta responsabilidade social é fundamentalmente um conceito ético que envolve mudanças nas condições de bemestar ligadas às dimensões sociais das atividades produtivas e suas ligações com a qualidade de vida na sociedade. Portanto, consubstancia-se na relação entre a empresa e seu ambiente de negócios.

\subsection{Desenvolvimento Sustentável}

Desenvolvimento sustentável significa atender às necessidades da geração atual sem comprometer o direito das futuras gerações atenderem a suas próprias necessidades. Nessa definição estão embutidos dois conceitos com os quais precisaremos doravante conviver. $\mathrm{O}$ primeiro é o conceito das necessidades, que podem variar de sociedade para sociedade, mas que devem ser satisfeitas para assegurar as condições essenciais de vida a todos, indistintamente. O segundo conceito é o de limitações, que reconhece a necessidade da tecnologia desenvolver soluções que conservem os recursos limitados, atualmente disponíveis e que permitam renova-los na medida em que eles sejam necessários às futuras gerações.

$\mathrm{Na}$ realidade a poluição industrial é uma forma de desperdícios e um indício da ineficiência dos processos produtivos até agora utilizados. Resíduos industriais representam, na maioria dos casos, perdas de matérias-primas e insumos. Na medida em que as empresas vão aderindo aos conceitos da Qualidade Total e se preocupam mais com a eficiência de seus processos produtivos, passa a haver uma convergência de interesses técnicos, econômicos e comerciais que tenderá a reduzir a geração de poluentes pela indústria.

\subsection{Autofinanciamento}

Do ponto de vista empresarial, quando se menciona meio ambiente sob o aspecto econômico a ideia inicial é a de que haverá aumento das despesas e o consequente acréscimo dos custos do processo produtivo. $\mathrm{Na}$ realidade um sistema de gestão ambiental estruturado, com metas 
estabelecidas, consegue se auto financiar, pois tecnologias limpas, mudanças de processo e tratamento de resíduos, torna possível contabilizar ganhos. De acordo com DONAIRE (1995:51): “algumas empresas, porém, tem demonstrado que é possível ganhar dinheiro e proteger o meio ambiente mesmo não sendo uma organização que atua no chamado 'mercado verde', desde que as empresas possuam certa dose de criatividade e condições internas que possam transformar as restrições e ameaças ambientais em oportunidades de negócios.".

Entre essas oportunidades podem ser citadas a reciclagem de materiais que tem trazido uma grande economia de recursos para as empresas; o reaproveitamento dos resíduos internamente ou sua venda para outras empresas através de Bolsas de Resíduos ou negociações bilaterais; o desenvolvimento de novos processos produtivos e como já foi dito com a utilização de tecnologias mais limpas ao ambiente, que se transformam em vantagens competitivas e até mesmo possibilitam a venda de patentes; o desenvolvimento de novos produtos para um mercado cada vez maior de consumidores conscientizados com a questão ecológica, geração de materiais de grande valor industrial a partir do lodo tóxico, estações portáteis de tratamento, miniusinas para uso de pequenas empresas e o aparecimento de um mercado de trabalho promissor ligado à variável ambiental que deverá envolver auditores ambientais, gerentes de meio ambiente, advogados ambientais, bem como o incremento de novas funções técnicas específicas.

\subsection{Accountability - Prestaçao de} Contas

A responsabilidade social empresarial é entendida como o relacionamento ético e a prestação de contas da empresa com todos os grupos de interesse que influenciam ou são impactados pela atuação da mesma (stakeholders), assim tanto no respeito ao meio ambiente quanto no investimento em ações sociais. É a expansão e evolução do conceito de empresa para além seu ambiente interno. $\mathrm{Na}$ medida em que a empresa esta inserida na sociedade, o bs e rva-s e uma rela ção d e interdependência entre ambas.

Este relacionamento com os denominados stakeholders e o meio ambiente deve estar de acordo com seus valores, políticas, cultura e visão estratégica.

O desenvolvimento da comunidade em que esta inserida, a preservação do meio ambiente, uma comunicação transparente interna e externa, o investimento no ambiente de trabalho, no bem estar dos funcionários, o retorno aos acionistas, a satisfação dos clientes e a sinergia com os stakeholders, são exemplos de ações que se caracterizam como prestação de contas e responsabilidade social.

Os investimentos em programas de gestão ética nas organizações surgiram a partir de demandas da sociedade, legislações, movimentos anticorrupção e de transparência internacional, se tornando questão estratégica, fator diferencial de competitividade e aumento de produtividade.

A ética empresarial envolve desde as práticas utilizadas pela empresa na venda de produtos ao mercado a fim de alcançar 
seus objetivos, até o relacionamento transparente com todos os "stakeholders".

"Stakeholders" são os grupos de interesse que se relacionam, afetam e são afetados pela organização e suas atividades. O termo "stakeholders" é mais abrangente do que "stockholders" que significa, exclusivamente acionista, enquanto que como "stakeholders", além dos acionistas, há os clientes, os fornecedores, os funcionários, a comunidade e todos os demais grupos sob o raio de influência próximo ou remoto da empresa. Um desses grupos poderá ser afetado pelas políticas ambientais praticadas pela entidade, daí o fato que para questões ambientais o orçamento tem que ser impositivo.

\subsection{Qualidade ambiental}

A conscientização ambiental dos dirigentes de uma empresa pode provocar alterações profundas em suas prioridades estratégicas e algumas mudanças de abordagem que vão modificar as atitudes e o comportamento de todos os seus funcionários. $\mathrm{O}$ quadro $\mathrm{n}^{\mathrm{o}} 1$ mostra, de forma esquemática, essas mudanças de abordagem motivadas pela conscientização ambiental.

A qualidade Ambiental é parte inseparável da Qualidade Total ansiada pelas empresas que pretendem se manter competitivas e assegurar sua posição em um mercado cada vez mais globalizado e exigente.

A Qualidade Ambiental consiste no atendimento aos requisitos de natureza física, química, biológica, social, econômica e tecnológica que assegurem a estabilidade das relações ambientais no ecossistema no qual se inserem as atividades da empresa.

Empresas que pretendam obter financiamentos no mercado internacional, que sejam fornecedoras de grupos internacionais e que almejem ser líderes nos segmentos da economia em que atuam não podem prescindir da Qualidade Ambiental como parte de sua imagem.

As ferramentas utilizadas para alcançar a Qualidade Ambiental são, em sua essência, idênticas aquelas utilizadas pela empresa para assegurar sua qualidade de produção: treinamento, plano de ação, controle da documentação, organização e limpeza, inspeções e análises periódicas da situação.

Para assegurar a Qualidade Ambiental devem-se prever, já na fase de concepção de um produto e no desenvolvimento do respectivo processo produtivo, soluções para resíduos que serão gerados. O desenvolvimento do produto e do processo, o gerenciamento dos resíduos resultantes e o gerenciamento da produção passam, assim, a ser tratados de forma integrada.

Essa integração requer o levantamento do chamado ciclo de vida do produto, identificando toda sua trajetória, desde as matérias-primas e insumos utilizados em sua fabricação, aos resíduos que gera até seu descarte final. Esse levantamento é importante do ponto de vista da Qualidade Ambiental, pois um produto pode ser ambientalmente limpo e correto apenas durante sua vida útil, porém não a montante, em processo produtivo, ou a jusante, em sua destruição após o uso. Por isso numa etapa seguinte seu ciclo de vida deve ser analisado para que se possa assegurar, de forma global, sua qualidade do ponto de vista ambiental. 
QUADRO N 1 - Mudanças na empresa através da conscientização ambiental

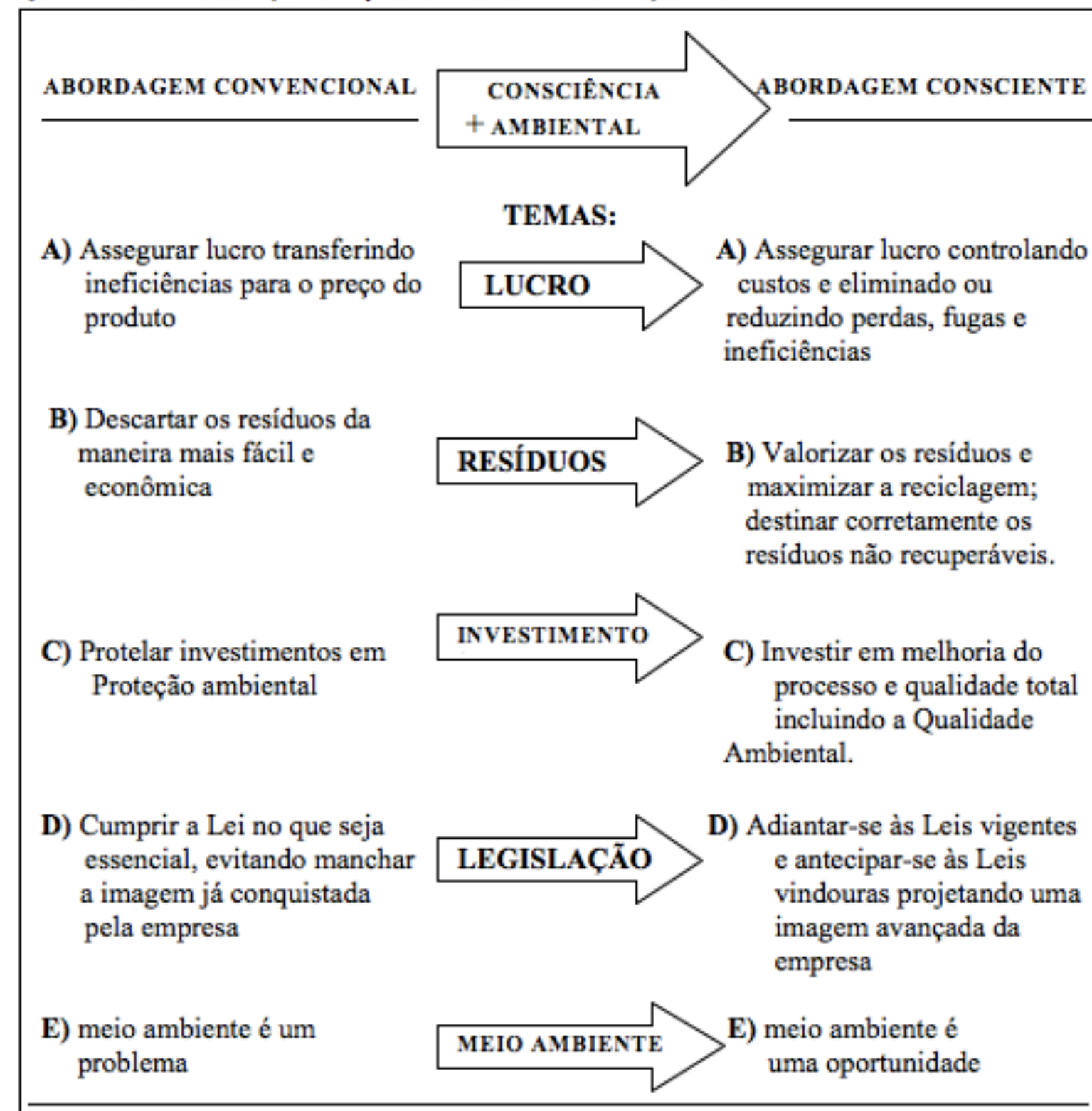

Fonte VALLE, Cyro Eiyer do, como se preparar para as normas ISO 14000: Qualidade Ambiental.

São Paulo: Pioncira, 2000.

\section{Contabilidade baseada em} atividades

O custeio por atividades, ou ABC (Activity Based Costing), tem se mostrado o mais apropriado, até o momento, para auxiliar a gestão estratégica de custos da empresa. Os custos indiretos têm aumentado significativamente nas últimas décadas, devido aos novos métodos de produção, exigindo, entre outros pontos maior flexibilidade, que exige maior necessidade de maior estrutura de apoio, do tipo: 
- Planejamento;

- Qualidade;

- Logística;

- Desenvolvimento;

- Meio ambiente;

\subsection{Diferencial de apresentação}

O controle de custos ambientais demonstra o nível de falhas existentes e o volume de gastos necessários para eliminar e/ou reduzir essas falhas, seja na forma de investimentos de natureza permanente ou de insumos consumidos no processo operacional.

De acordo com Ribeiro (1998: 69), “os custos ambientais devem compreender todos aqueles relacionados, direta ou indiretamente, com a proteção do meio ambiente, como:

- Todas as formas de amortização (depreciação e exaustão) dos valores relativos aos ativos de natureza ambiental possuídos pela companhia;

- Aquisição de insumos próprios para controle/redução/eliminação de poluentes;

- Tratamento de resíduos dos produtos;

- Disposição dos resíduos poluentes;

- Tratamentos de recuperação/ restauração de áreas contaminadas;

- Mão de obra utilizada nas atividades de controle/preservação/ recuperação do meio ambiente.

O processo de identificação e quantificação dos custos relacionados ao meio ambiente exige envolvimento de vários departamentos da empresa, como Compras, Meio Ambiente, Saúde e Segurança, Finanças e Contabilidade. Identificar e trilhar dados de custos ambientais tem por finalidade chave o levantamento de informação necessária para valorar, e talvez, realocar o uso de ativos da empresa, ou seja, tomar melhores decisões sobre investimentos. Uma das consequências desse exercício é o reexame do valor adicionado de cada atividade necessária. Uma vez diagnosticado que a atividade é primordial, deve-se verificar a possibilidade de substituição desta, por outra.

Os tipos de custos que são atribuídos ao meio ambiente são classificados em quatro categorias, como descreveu o "Pollution Benefits Manual" publicado pela U.S. Environmental Protection Agency - EPA e em subsequentes publicações, sendo a mais a 'EPA's An Introduction Environmental Accounting as a Business Management Tool: Key Concepts and Terms (1995). Os custos ambientais também foram classificados em quatro categorias:

- Custos Convencionais: inclui os custos que, na maior parte das vezes, recebem atenção especial na contabilidade gerencial, tais como investimentos em equipamentos, matéria-prima, mão de obra e materiais indiretos. Dessa forma, os custos convencionais incluem todos aqueles associados com os aspectos ambientais tangíveis de tais processos e atividades. Seu controle conduz ao aumento da eficiência produtiva por eliminar o desperdício. 
- Custos potencialmente ocultos: são aqueles ligados a todas as atividades necessárias para que a empresa se mantenha em conformidade com as leis e outras políticas ambientais inerentes à própria organização. A integração de exigências regulatórias nos planos de negócio enfoca os custos de conformidade para adequar produtos e processos e expõe formalmente custos ocultos. Como exemplos, destacam-se o monitoramento ambiental, treinamento, relatório ambiental, entre outros.

- Custos em Contingências: envolvem todos os gastos que podem ou não ocorrer devido a futuros custos de regulamentações, multas e penalidades, gastos com recuperação de recursos naturais danificados, etc. Conhecer o fato gerador de tais custos, antecipadamente, possibilita à empresa definir ações a fim de evitá-los.

- Custos de Imagem e Relacionamento: envolve a percepção e o relacionamento que os acionistas, comunidade e governo desenvolvem com a companhia. Apesar de difícil quantificação o desempenho ambiental pode melhorar ou prejudicar o relacionamento da empresa com terceiros, e os impactos gerados podem ter custos e/ou implicações financeiras.

A gestão dos custos ambientais permitirá a avaliação dos possíveis riscos ambientais que a empresa esteja assumindo. Estas contingências precisam ser conhecidas pelos gestores e devem ser retratadas, sob o ponto de vista gerencial da empresa.

\subsection{Custos ambientais por processos}

Em se tratando de atividades voltadas ao controle, à proteção e preservação ambiental, os custos segregados por processos tem a finalidade de contribuir para assegurar que os procedimentos, que tem por finalidade proteger e preservar o meio ambiente estão consumindo recursos dentro dos parâmetros previstos, e, portanto, estariam produzindo os resultados técnicos esperados. Obviamente que esta análise deve feita em conjunto com as técnicas operacionais, pois, os gastos podem estar em conformidade com os previstos, mas os níveis de poluição decorrentes do processo podem estar acima do que o esperado.

$\mathrm{O}$ monitoramento dos custos ambientais por processos, principalmente quando o processo tem por objetivo específico atividades relacionadas ao controle, proteção e preservação ambiental, além de buscar assegurar a conformidade das medidas empreendidas com aquelas realmente necessárias, permite ainda, a obtenção de dados que possibilitam a avaliação de continuidade ou terceirização. No caso dos processos específicos, os quais requerem que a empresa monte uma estrutura especial para a realização do referido processo, pode-se apresentar dados em que se vislumbre que a contratação dos serviços de terceiros pode resultar em custos menores para a empresa. Segundo CHING (1995:22) "a gestão de processos e atividades deve ser conduzida 
de forma que atinja os quatros objetivos a seguir"

- Reduzir custos;

- Diminuir o ciclo de tempo;

- Melhorar a qualidade;

- Agregar valor ao cliente em termos de serviços, flexibilidade etc.

Os objetivos acima se enquadram também entre os objetivos do sistema de gerenciamento ambiental, pois na medida em que se reduzem custos, perder-se-á menos tempo na elaboração de produtos que serão descartados como resíduos da produção. Assim sendo, sem resíduos há melhoria de qualidade ambiental, tanto no produto como no processo de elaboração, agregando valor ao cliente, pois elimina problemas de recusa do produto em função de qualidade ambiental.

Caso os gastos orçados para controle ambiental não se efetivem em sua plenitude, a empresa com essa "economia" pode estar deixando de implantar projetos planejados para diminuir a poluição de meio ambiente, o que deve ser investigado pela Controladoria, pois se o gasto orçado não foi realizado, por qualquer motivo, a variação orçamentária não deve ser considerada como favorável, mas sim desfavorável, pois pode afetar resultados futuros.

\section{Gestão ambiental baseada em} atividades

A gestão ambiental baseada em atividades deve pressupor a definição dos vários processos gerenciais da função Meio Ambiente, essa função teria o mesmo status na empresa das demais funções, como Marketing, Finanças, Produção, Recursos Humanos e outras. Essa função poderia ser alocada à Logística da empresa ou ficar subordinada diretamente à Presidência, constituindo uma Diretoria autônoma. De acordo com FURLAN (1997:37), uma lista parcial dos processos gerenciais da função 'Meio Ambiente', de uma 'Usina de Geração de Energia', poderiam contemplar:

"Planejamento do meio ambiente; Controle de poluição; Tratamento dos efluentes; Desmatamento e reflorestamento; Piscicultura; Controle de insetos; Programa básico ambiental; Recuperação ambiental; Acompanhamento meteorológico; Proteção ambiental; e, Elaboração de projetos de poluição harmônica”. FURLAN (1997:38).

Para este último processo, FURLAN, propõe a definição: "Estudar o fenômeno de poluição harmônica (distorção nas ondas de tensão e corrente), provocada por determinadas cargas especiais de consumidores que colocam em risco a integridade de equipamentos elétricos e afetam a qualidade da energia elétrica entregue, recomendando-se as medidas necessárias".

Posteriormente, cada processo gerencial deveria ser detalhado por atividades, evidentemente, de acordo com a necessidade de detalhes gerenciáveis, sempre levando em consideração a clássica confrontação do custo da informação em relação ao respectivo benefício.

\subsection{ABMI aplicado à gestão ambiental}

A gestão ambiental baseada em atividades (Activity Based Management) consiste em nortear as diferentes decisões com relação ao meio ambiente, de acordo 
com os relatórios de custos das atividades ambientais.

Para tanto, a modelagem dos diferentes sistemas ambientais, deve estar voltada para a definição dos processos ambientais, exemplificados no item anterior, detalhados em atividades. A visão sistêmica desses processos ajuda a modelagem dos sistemas ambientais. Adequando-se ao proposto por POLYA (1973), in CHRISTOFOLETTI (2000:25), a questão da modelagem dos sistemas ambientais, assemelha-se à solução de problemas matemáticos, ou seja:

“a) Compreender o problema, questionando, Qual é a questão? b) estabelecer um plano para a solução do problema: Como se pode resolvê-lo? c) executar o plano: Qual é uma resposta? d) checar a adequação da resposta: A resposta está correta?" (POLYA, 1973 in CHRISTOFOLETTI, 2000:25).

Dessa abordagem, poder-se-ia inferir os sistemas de modelos de custos ambientais, que seriam básicos para a gestão ambiental baseada em atividades. A construção desses modelos deveria seguir quatro etapas básicas:

1) Formulação, definindo-se os objetivos do modelo; 2) Verificação, validação prévia; 3 ) Calibragem ou Nivelamento; e 4) Análise e Avaliação do Modelo. Em cada etapa, seriam testadas as premissas. Caso essas premissas não atendessem o objetivo geral e de cada fase, elas teriam que ser discutidas e reformuladas. O conjunto de sistemas, processos e atividades, constituiriam o Sistema de Informações Ambientais Gerencias - SIAG. (POLYA, 1973 in CHRISTOFOLETTI, 2000:25).

\section{Passivos ambientais}

O passivo ambiental deve ser reconhecido nos relatórios financeiros se é de ocorrência provável e pode ser razoavelmente estimado, existindo vários padrões de "contingências" que devem ser usados para caracterizar o que seria um evento de ocorrência provável. No caso de haver dificuldades na estimação do valor de um passivo ambiental, deverá ser provisionado um valor razoável, sendo registrados os detalhes dessa estimativa em notas explicativas.

O passivo ambiental que não será liquidado no curto prazo, expressa preferência pela medição através do método do valor presente de uma estimativa de custos e despesas futuras, realizada com base em custos correntes que a atividade requer e supondo a existência de exigência legal e/ou outras, alertando, que a incerteza inerente a essa abordagem é minimizada se:

\footnotetext{
"A taxa de desconto para o valor presente for baseada na taxa de risco semelhante à dos títulos de governo; Os avanços tecnológicos que se espera que aconteçam no curto prazo forem levados em conta (note-se que os avanços de longo prazo não devem ser considerados); A expectativa de inflação for levada em conta; $O$ total do passivo ambiental for revisado a cada ano e ajustado por qualquer mudança relativa às estimativas de gastos futuros anteriormente assumidos; e As estimativas de obrigações adicionais forem baseadas em fatores relevantes para $o$ período em que essas mesmas obrigações s urja m” ( P L L A, 1973 i n CHRISTOFOLETTI, 2000:25).
}

\section{Tendências para as empresas serem responsáveis}

Diversos são os caminhos hoje existentes a serem trabalhados por uma organ i z a çã o n a bu s c a pelo desenvolvimento sustentável. A destinação dos resíduos gerados pela sociedade se torna mais complexa à medida que aumentam a população o nível de 
industrialização e o consumo de material. Como consequência, para se enfrentar a carência de locais adequados para lançar esses resíduos iniciou-se a busca por soluções mais eficazes do que a dispersão dos mesmos no meio ambiente. Em vez de simplesmente dispor seus resíduos, passouse a procurar alternativas mais lógicas, que se propõem a tratar, reaproveitar, minimizar ou até eliminar a geração dos resíduos, contribuindo, cada uma dessas alternativas, em escala crescente, para a solução efetiva do problema.

Essas soluções são escolhidas a partir de abordagens distintas, observadas sob os seguintes ângulos:

\begin{abstract}
"Minimizar - abordagem preventiva, orientada para reduzir o volume e o impacto causado pelos resíduos. Em casos excepcionais, pode-se eliminar completamente a geração do resíduo. Valorizar - abordagem orientada para extrair valores materiais ou energéticos que contribuem para reduzir os custos de destinação dos resíduos e, em alguns raros casos geram receitas superiores a esses custos. Reaproveitar - abordagem corretiva, orientada para trazer de volta ao ciclo produtivo matérias-primas, substâncias e produtos extraídos dos resíduos. Dispor abordagem passivo orientada para conter os efeitos dos resíduos, mantendo-os sob controle, em locais que devem ser monitorados" (POLYA, 1973 in CHRISTOFOLETTI, 2000:25).
\end{abstract}

As abordagens pelo reaproveitamento, por sua vez, pode ter três enfoques distintos:

"Reciclagem, quando há o reaproveitamento cíclico de matérias-primas de fácil purificação como, por exemplo, papel, vidro, alumínio etc. Recuperação, no caso de extração de algumas substâncias dos resíduos, como, por exemplo, óxidos, metais etc. Reutilização ou reuso, quando o reaproveitamento é direto, sob a forma de um produto, tal como as garrafas retornáveis e certas e mbalagens reaproveitáveis" (POLYA, 1973 in CHRISTOFOLETTI, 2000:25).
As tecnologias limpas que visam a eliminar ou reduzir a geração do resíduo, a partir do processo produtivo.

" $1^{\circ}$ - Os tratamentos convencionais que
visam a reduzir os efeitos dos resíduos,
através de processos físicos, químicos,
biológicos ou térmicos. $2^{\circ}-$ As tecnologias
novas que visam, através de pesquisa e
desenvolvimento, encontrar soluções para
problemas específicos que carecem de
soluções próprias, ou que requerem soluções
a lternativas" (PO LYA, 1973 in
CHRISTOFOLETTI, 2000:25).

As soluções encontradas para encaminhar adequadamente os problemas ambientais obedecem, portanto, a uma sequencia lógica e natural, expressa pelas seguintes providências:

$1^{\circ}$-Minimização da geração de resíduos através de modificações no processo Produtivo, ou pela adoção de tecnologias limpas, mais modernas e que permitem, em alguns casos, eliminar completamente a geração de materiais nocivos; $2^{\circ}$ Reprocessamento dos resíduos gerados, transformando-os novamente em matéria prima, ou utilizando-os para gerar energia; $3^{\circ}$ - Reutilização dos resíduos gerados por uma indústria como matéria-prima para outra indústria; $4^{\circ}$ - Separação de substâncias nocivas das não nocivas, reduzindo o volume total de resíduo que deva ser tratado ou disposto de forma controlada; $5^{\circ}$ - Processamento físico, químico ou biológico do resíduo, de forma a torna-lo menos perigoso ou até inerte, possibilitando sua utilização como material reciclável; $6^{\circ}$ - Incineração, com o correspondente tratamento dos gases gerados e a disposição adequada das cinzas resultantes; $7^{\circ}$ - Disposição dos resíduos em locais apropriados, projetados e monitorados de forma a assegurar que não venham, no futuro, a contaminar o meio ambiente. Valle (2000).

O professor Cyro Eyer do Valle (2000) enfatiza que: "essas soluções, na sequência em que estão apresentadas, decrescem em eficácia, pois partem de um conceito de eliminação do problema (o de evitar a geração do resíduo) e terminam na 
disposição vigiada do problema não solucionado (isto é, um aterro ou uma lagoa)".

A figura 1 sintetiza essa sequencia e mostram que, na maioria dos casos, as soluções mais lógicas, mesmo de complexidade crescente em sua aplicação, acarretam custos globais decrescentes para a sociedade e contribuições mais eficazes para solucionar os problemas ambientais.

Algumas atitudes de ordem eminentemente prática ajudam a equacionar os problemas acarretados pela geração dos resíduos e contribuem para a escolha da solução mais adequada em cada caso:

Redução das quantidades de resíduos evitando misturar materiais contaminados, que irão requerer tratamento ou disposição especial, com matérias não contaminados, que poderão ser reaproveitados. Secagem ou desidratação dos resíduos, reduzindo seu volume e seus custos de transporte e facilitando a disposição das frações secas.
Extração, por processos físicos, químicos ou biológicos de frações valiosas contidas nos resíduos, reduzindo os custos de destinação das frações remanescentes (Valle, 2000).

De outra parte, alguns fatores que não são de ordem técnica afetam também a escolha da solução. São eles:

a)Fatores econômicos: custo da tecnologia e dos investimentos necessários; valor dos materiais recuperados; comparação entre os custos de tratamento e de disposição final etc.

b)Fatores de imagem da empresa: soluções mais limpas, mesmo que sejam mais.

c) Dispendiosas; decisão de não depender de aterros ou do processamento de seus

d)Resíduos por terceiros etc.;

Desenvolvimento da abordagem para solucionar os problemas com resíduos: 
Fig1: Cyro Eyer do Valle (2000).
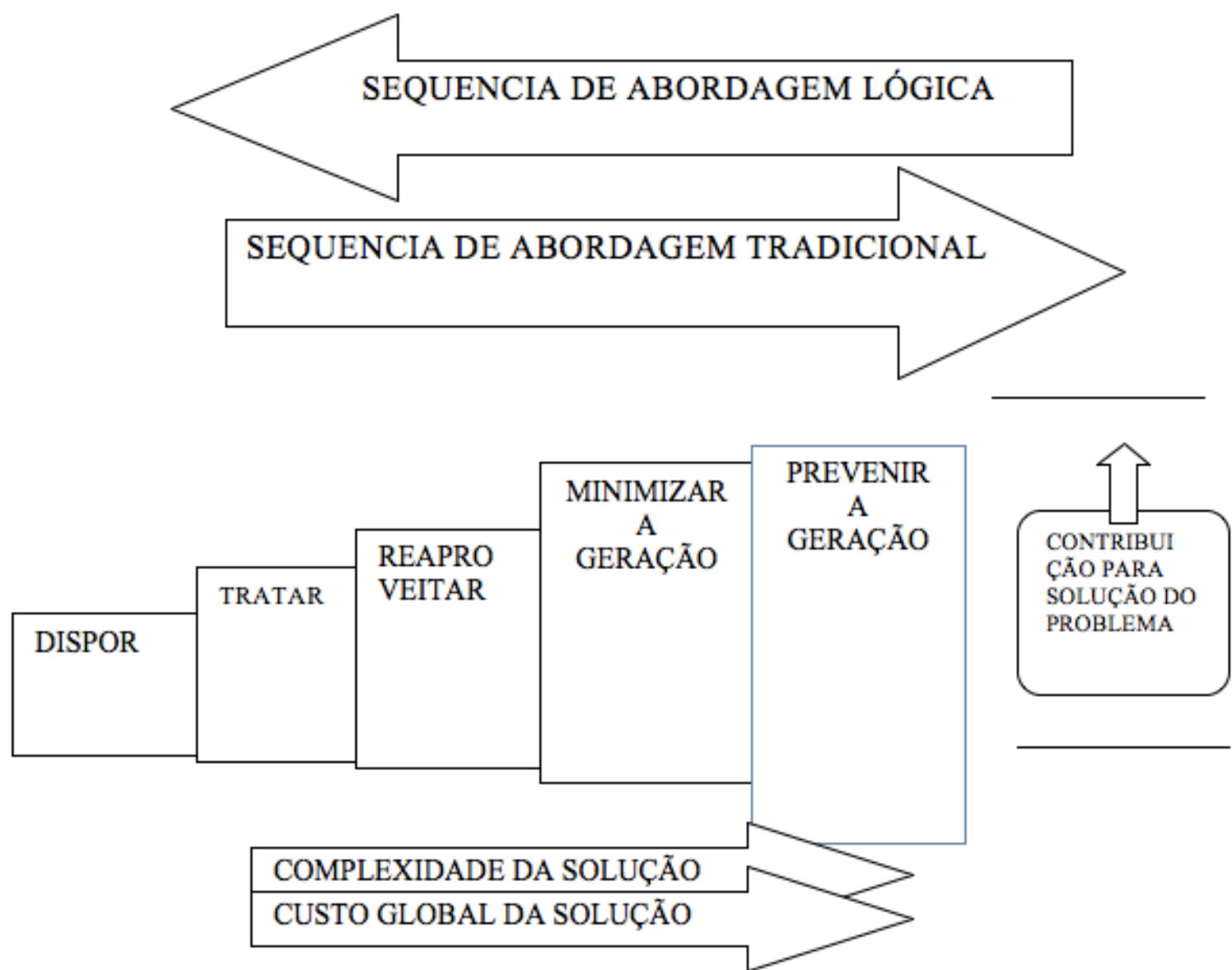

Fonte da Fig. 1: Abordagem para solucionar os problemas com resíduos: Cyro Eyer do Valle (2000)

\subsection{Comtroladoria da gestão} ambiental

Considerando que o sistema de gestão ambiental consome recursos, ressaltamos a indispensável, integração entre o gerenciamento ambiental e a gestão estratégica de custos.

$\mathrm{Na}$ área ambiental, seja na forma preventiva, de controle ou de recuperação os gastos tem significativo impacto sobre o patrimônio das empresas e, por esta razão, deve ser alvo de criteriosas estratégias, de forma a garantir o sucesso dos sistemas de gerenciamento ambiental adotados pelas companhias e, consequentemente, a continuidade dos negócios destas.

A gestão estratégica de custos tem se mostrado uma necessidade premente para a conquista e manutenção de espaços no mercado nacional e internacional, cuja concorrência torna-se cada vez mias acirrada.

A contabilidade por atividades tem um papel importante, podendo propiciar informações valiosas para a gestão econômica da empresa, ao custear a menor unidade de consumo de recursos, que são as atividades. Estas consomem os recursos; 
portanto, o custo destes recursos deve ser apropriado às atividades que os exigiram. Os produtos e processos consomem atividades, recebendo, por conseguinte, os custos dos recursos consumidos pelas mesmas. Usando-se esta metodologia se elimina, consideravelmente, a necessidade de rateio dos custos indiretos e, consequentemente, as arbitrariedades provocadas pelo subjetivismo da escolha dos parâmetros para a distribuição de tais custos e se identifica, por fim, os custos ambientais em função das atividades executadas inerentes ao controle ambiental.

O correto custeamento das atividades relativas ao controle, preservação e recuperação ambiental pode resultar na redução de custos, em função da eliminação de perdas e desperdícios de recursos, como também o aumento de receitas em decorrência de melhorias que podem ser implantadas a partir da identificação de falhas na utilização dos recursos.

$\mathrm{O}$ conhecimento dos custos reais na área ambiental, principalmente a forma como se distribuem no processo operacional, proporciona condições para o estudo, análise e avaliação do grau de essencialidade das atividades desenvolvidas, do montante de capital consumindo pelos processos de proteção ambiental, evidenciado, consequentemente, a partir da análise da relação custo/ benefício, a necessidade de reestruturação, de novos investimentos, além de fornecer subsídios para a tomada de decisão sobre ser ou não necessário buscar capital adicional para atender tais necessidades.

Informações quanto ao consumo de recursos pelas atividades de proteção ambiental e pelos produtos possibilitam melhores condições para a determinação de preço e ainda uma real avaliação dos custos/benefícios gerados pela sua manutenção.

\subsection{Indicadores de gestão}

A apresentação de indicadores de desempenho ambiental torna-se importante no processo de fornecer informações em que o processo de transparência passa pela padronização e começa a utilizar estes indicadores que procurarão sintetizar as informações quantitativas e qualitativas relativas ao seu desempenho ambiental.

Indicadores de desempenho ambientais confiáveis são medidas necessárias para conferir transparências aos negócios das empresas. Esses indicadores serão mais valiosos se forem transparentes no tempo, se consistirem em indicadores relativos e se forem comparáveis com indicadores de outras empresas. Outras qualidades importantes requeridas para esse tipo de indicador são a sua padronização e a sua aceitação pelos usuários.

Estes indicadores vêm sendo progressivamente incorporados pelas empresas, na medida em que as empresas ficam conscientes, que além de reduzir o impacto das atividades empresariais no meio ambiente, aumentam a rentabilidade. Podendo ser dividido em:

Em indicadores de processo, de sistemas eco financeiros, podem ser divididos em outros dois tipos: os absolutos, quando são itens simples, tais como o custo ambiental do período; e os relativos, que consistem em uma razão existente entre dois ou mais itens por período, por exemplo, o custo ambiental 
apresentado como um percentual do faturamento.

Existem três combinações de possíveis pares de indicadores que podem ser usados para descrever o desempenho ambiental:

- Indicador financeiro relacionado com outro indicador financeiro, como por exemplo, passivo ambiental/patrimônio líquido;

- Indicador financeiro relacionado com indicador ecológico, como, por exemplo, emissão de $\mathrm{CO} 2 /$ unidade de produto produzido; e

- Indicador ecológico relacionado com outro indicador ecológico, como por exemplo, resíduo produzido/recurso utilizado.
Considerações Finais

As informações dos resultados obtidos pelo custeamento das atividades ambientais servirão como subsídio para as decisões internas em relação às medidas necessárias para a continuidade do sistema de gerenciamento ambiental e consequentemente a continuidade da empresa, serão também de grande utilidade para que a empresa preste contas de sua responsabilidade social à comunidade onde está inserida e aos demais com quem mantém relações. As exigências crescentes, verificadas atualmente num mercado competitivo, além da preocupação com o esgotamento e o comprometimento dos recursos naturais, levam as empresas a observarem as disposições da legislação ambiental aplicável de forma a se enquadrarem nos padrões superiores de qualidade de seus processos e produtos.

\section{Referências Bibliográficas}

AZAMBUJA, M. O Brasil e a Cidadania Empresarial, Jornal Valor, 20/04 São Paulo, 2001.

BARRETO, M. G. P. A simplicidade de um sistema de custos da qualidade. Anais do VI Congresso Brasileiro de Custos, São Paulo, 1995.

BERGAMINI JUNIOR, S. "Custos emergentes na Contabilidade Ambiental" Revista Pensar Contábil - Edição Especial da 50 Convenção dos Contabilistas do Rio de Janeiro, Out/2000. BERGAMINI JUNIOR, S. “Custos e Riscos Ambientais" Seminário de Contabilidade Ambiental auditório do BNDES dias 5 e 6 - Nov/98.

BONELLI. V. V. ROBLES JR, A. Gestão da qualidade e do meio ambiente: enfoque econômico financeiro e patrimonial. São Paulo: Atlas, 2006.

BORNIA, A, C. Mensuração dos Desperdícios. Anais do VII congresso internacional de Custos, Leon-Espanha, 2001.

BRIMSON, J. Contabilidade por Atividades: Uma abordagem de custeio baseado em Atividades. São Paulo: Atlas, 1996.

CHRISTOFOLETTI, A, Modelagem de Sistemas Ambientais, Editora Blücher, 2000. 
CROSBY, P. B., Qualidade é Investimento. 5a . ed. Rio de Janeiro; José Olympio, 1979. CRC SP Conselho Regional de Contab. São Paulo. "Passivo Ambiental” XIII - Ciclo de Palestras CRC - SP e Ibracon, Pricewaterhouse e Coopers - Dez/1999.

DONAIRE, D. Gestão Ambiental na empresa, São Paulo: Atlas, 1995.

FURLAN, J. Dom, Modelagem de Negócio, Makron Books, São Paulo, 1997.

LERENA BELLO, L.; CARRAZZANA A, T., Los Costos de La Calidad como Herramienta de la dirección. Anais do VII congresso internacional de Custos, Leon-Espanha, 2001.

MOURA, J. A. M.. Os frutos da qualidade - A experiência da Xerox do Brasil: São Paulo:

Makron Books, 1994.

MOURA, L. A, A.. Economia Ambiental: Gestão de Custos e Investimentos, São Paulo: Ed. Juarez de Oliveira, 2000.

PORTER, M, 1 E. Vantagem Competitiva. Rio de Janeiro; 1989.

REIGOTA, M.. "Meio Ambiente e Representação Social” Ed. Corte: São Paulo, 1995.

RIBEIRO, M. S., Contabilidade e Meio Ambiente. Dissertação de Mestrado Apresentada à FEA/USP. São Paulo.1992.

RIBEIRO, M. S. Custeio das Atividades de Natureza Ambiental, Tese de Doutorado apresentada à FEA/USP. São Paulo.1998.

ROBLES JUNIOR. Custos da Qualidade: uma estratégia para a competição. Global; Atlas, 1994.

ROBLES JUNIOR, A; BONELLI, V. V, Apuração dos Custos da Qualidade e dos Custos Ambientais Através da Contabilidade Baseada em Atividades, ENANPAD/ 2001.

VALLE, C. Como preparar para as normas ISO 14.000: Qualidade Ambiental: O Desafio de ser competitivo protegendo o Meio Ambiente. $3^{\text {a }}$ ed. São Paulo: Pioneira, 2000.

ZARDO, L. M. P., A importância dos custos da qualidade na gestão Empresarial. Anais do VI Congresso Brasileiro de Custos, São Paulo, 1999. 